\section{Preoperative usage of ultrasound biomicroscopy in pediatric cataract}

\section{Uso pré-operatório de biomicroscopia ultrassônica em catarata pediátrica}

\section{Dear Editor:}

I read the article"Epilens membrane simulating cataract in children with uveitis: a report of three cases" by Paiva et al. with great interest ${ }^{(1)}$. Three cases were presented that were diagnosed as cataract secondary to uveitis but that were understood to have received treatment for pupillary membrane intraoperatively. I congratulate the authors for their attention and good management.

Cataract surgery is a radical operation in children ${ }^{(2)}$ and may cause quite a few complications; patients will also require follow-up after operation. The indication for cataract surgery in children should be evaluated carefully. Preoperative examination and imaging are critical for deciding on whether to operate or not and to identifying operation strategy. Ultrasound biomicroscopy (UBM) could be a good imaging method to diagnose epilens membrane in these cases $^{(3)}$.
UBM is a non-invasive method that allows imaging of structural details of the anterior segment and the lens. UBM could visualize the epilens membrane and divulge the transparency of the lens. Nevertheless, it is a great advantage to be able to differentiate the membrane intraoperatively without damaging the anterior capsule.

Abdullah Kaya'

Submitted for publication: October 26, 2015

Accepted for publication: November 9, 2015

Department of Ophthalmology, Anittepe Military Dispensary, Cankaya, Ankara, Turkey.

Funding: No specific financial support was available for this study.

Disclosure of potential conflicts of interest: None of the authors have any potential conflict of interest to disclose.

Corresponding author: Abdullah Kaya. Anittepe Military Dispensary. Department of Ophthalmology Cankaya, Ankara - Turkey - E-mail: abdullahkayamd@gmail.com

\section{REFERENCES}

1. Paiva R, Nascimento H, Salomão G, Freitas L, Muccioli C, Belfort R Jr. Epilens membrane simulating cataract in children with uveitis: a report of three cases. Arq Bras Oftalmol. 2015;78(5):326-7.

2. Pavlović S. [Cataract surgery in children]. Med Pregl. 2000;53(5-6):257-61. Review. Croatian.

3. Ünsal E, Eltutar K, Muftuoglu I, Akcetin TA, Acar Y. Ultrasound biomicroscopy in patients with unilateral pseudoexfoliation. Int J Ophthalmol. 2015;8(4):754-8.

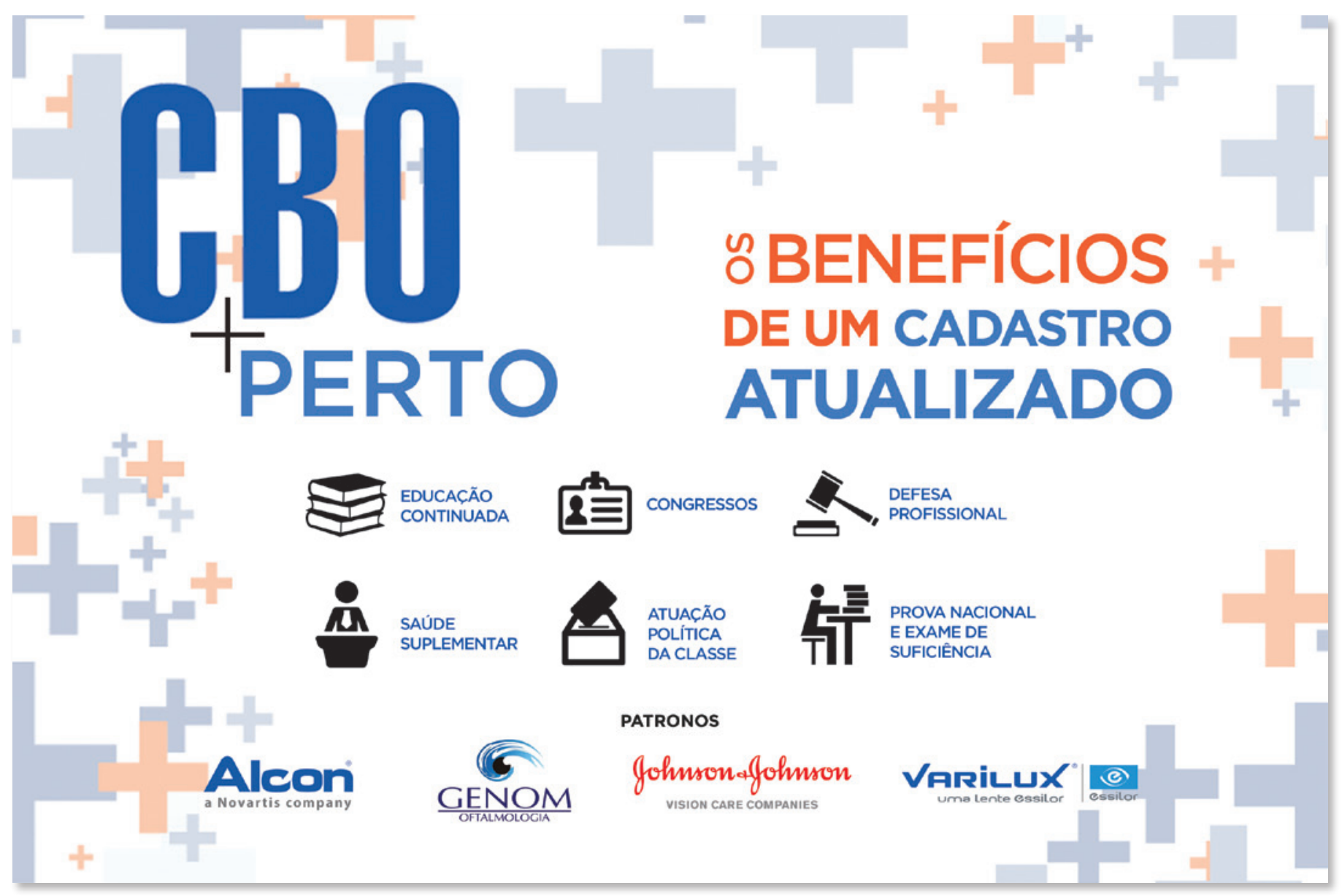

